\title{
Impact of Knowledge Infrastructure on the Organizational Performance: An Empirical Investigation of Education Sector of Pakistan
}

\author{
Nida Shabbir \\ Bahauddin Zakariya University, \\ Multan, Pakistan
}

\author{
Sadia Anwar \\ Comsats Institute of Information Technology, \\ Sahiwal, Pakistan
}

\begin{abstract}
Knowledge management is gaining particular attention because of its increasing scope globally. A sound knowledge infrastructure is inevitable for every organization if it wants to perform better. This study aims to find that how is the knowledge infrastructure in the education sector of Pakistan. It seeks to find the impact of knowledge infrastructure on the performance of organization. It also suggests that what strategies could be formulated in order to increase the organizational performance through a well-designed knowledge infrastructure. Education sector is selected as population while universities have been selected as sample. Empirical research design and exploratory study have been emphasized in this paper. Quantitative research method is used. Data are collected through questionnaires distributed to teaching and administration staff of the universities. Findings of the paper include the conceptual framework which shows the relationship between knowledge infrastructure and organizational performance. It highlights the elements of the knowledge infrastructure that have an impact on the performance of the organization. This study will be helpful for educational institutes to understand how well their knowledge infrastructure is and what steps or strategies can be formulated to improve the knowledge infrastructure thereby increasing the organizational performance.
\end{abstract}

Keywords: knowledge infrastructure, elements of knowledge infrastructure, organizational performance

\section{Introduction}

From last few years, knowledge management has become one of the most interesting and debatable topics for organizations in various sector. Organizations are now interested to implement the knowledge management practices because of its need of the time. Increased globalization and advancement in technology requires organizations to struggle in order to achieve competitive advantage. Knowledge has become a factor of production after land, labor, and capital (Sher \& Lee, 2004).

In order to create value and to achieve competitive advantage, knowledge management is inevitable. Chen (2011) supported this statement by arguing that knowledge is an important asset of the organization that helps to create value and competitive advantage. Knowledge management supports in the planning, organizing, motivating, and controlling of people, processes, and systems in an organization to make sure that its knowledge-related 
assets are continuously improved and effectively employed (Rajesh, Pugazhendhi, \& Ganesh, 2011).

One of the most significant advantages of knowledge management practices is that it results in increased organizational performance. Many organizations believe that performance of an organization does not depend on the effective use of the natural resources or tangible assets, but depends on how knowledge is managed (Lee \& Sukoco, 2007). An organization strategically spends enormous amount of resources on the knowledge management as it ensures them an improved organizational performance. A research study conducted in Croatia proposes that effective knowledge management practices have a positive impact on organizational performance in terms of company innovation, product improvement, and employee improvement (Kiessling, Richey, Meng, \& Dabic, 2009).

For an organization to increase its performance, there must be a sound knowledge infrastructure to support its knowledge management activities. There are many factors that enable knowledge management in an organization and support the knowledge management infrastructure to increase the efficiency of the knowledge management activities. Technology, organizational structure, and organizational culture are those significant enablers (Gold, Malhotra, \& Segars, 2001). An organization, if wants to implement knowledge management, needs a strong infrastructure that will lead the knowledge management in the organization.

In Pakistan, knowledge management is an emerging concept and it needs special attention particularly in the education sector. People are living in an era of knowledge organization and it is vital for knowledge management organizations to create, share, and store knowledge (Santo, 2005). Unfortunately, the education sector in Pakistan does not realize the importance of knowledge management. There are many educational institutes that are last to consider knowledge management as a part of their assets. Because of increased globalization, it is challenging for the educational institutes to prepare the students to compete in knowledge society. It becomes more complicated when institutes become ignorant regarding the knowledge management. Therefore, it requires the educational institutes especially universities to constantly evolve, investigate, analyze, predict, and give response to the opportunities generated as a result of knowledge creation (Stukalina, 2008).

The purpose of this paper is to examine how the knowledge infrastructure in the education sector of Pakistan is and what is the impact of a knowledge infrastructure on the organizational performance. It also suggests that what strategies could be formulated in order to increase the organizational performance through a well-designed knowledge infrastructure.

\section{Literature Review}

\section{Knowledge Management Processes}

Knowledge management processes are vital for knowledge management. Many authors have defined knowledge management processes in their own ways. According to Gold et al. (2001), information technology (IT), organizational structure, and organizational culture are considered as infrastructure capabilities, while knowledge and acquisition, conversion, application, and protection are known as process capabilities. Ernst \& Young (1998) identified four knowledge management processes which include planning, acquiring, applying, and assessing. Lee and Kim (2001) argued that there are three knowledge management processes including knowledge accumulation, integration, and reconfiguration. Knowledge accumulation can be done by acquiring knowledge from various external and internal sources. On the other hand, the most significant knowledge management processes are integrating and reconfiguring of knowledge, because environment keeps on changing. Wiig (1995) explained that knowledge management processes consist of four stages, i.e., creation, 
manifestation, use, and transfer of knowledge. Creation and manifestation means how knowledge is created and established in the minds of the people in addition to the culture, procedures, and technology. Use of knowledge is about how it is used in making decisions and other knowledge-related work by individuals and businesses. Transfer means how people learn and exchange the knowledge with others.

According to Ruggles (1997), knowledge management processes comprise of knowledge generation, codification, and transfer. Knowledge generation embraces all activities which highlight knowledge which is new to the individual, to the group, or to the world. Knowledge codification is the capture and depiction of knowledge so that it can be used again and again either by an individual or by an organization. Knowledge transfer includes the movement of knowledge form one place to another and its consequent absorption. Nevis, Anthony, and Gould (1995) divided knowledge processes into acquisition, sharing, and utilization. The creation or development of skills, insights, and relationship is known as knowledge acquisition. Knowledge sharing on the other hand is the distribution or circulation of what has been learned. Knowledge utilization means integration of learning so that it is available largely and can be comprehend to new situations.

Knowledge identification. Effective knowledge management practices face some obstacles. Knowledge identification is one of the key obstacles organizations come across most commonly. Organizations do not know what they know. Previous studies and findings on knowledge management reveal what knowledge exists in the organization and what knowledge is required in the organization is one of the most important processes of knowledge management. This important process is called as knowledge identification. Organizations must know what is their internal knowledge and where this knowledge exists (Jennex \& Olfman, 2004; Probst, Raub, \& Romhardt, 2000; Reinhardt, 2001). Organizations should not ignore to understand their current status of knowledge practices as it will help to know that to what extent an organization is involved in knowledge management. Also, the relation between knowledge identification and knowledge creation should be effectively leveraged (Nonaka \& Takeuchi, 1995). Findings of many authors reveal that it is necessary to identify that knowledge practices in an organization are existing or not. At least organizations should be aware how to identify knowledge. It will help the organization improve its performance by developing knowledge management culture (Lee \& Choi, 2003).

If an organization fails to practice knowledge identification, it leads to occurrence of several problems. Firstly, not identifying internal knowledge means failure to apply right knowledge at right time in right form. Secondly, it might leads to repetition of various projects and tasks thereby wasting resources (Robinson, Carrillo, Anumba, \& Al-Ghassani, 2005). As a matter of fact, failure to identify knowledge can result in loss of billions which also shows that organizations are poor at managing (Stewart, 2002). Therefore, knowledge identification as a key process of knowledge management should not be ignored as it also enhances knowledge sharing and knowledge creation (Riege, 2005).

Knowledge storage. Considering knowledge as a vital resource, organizations recognize the value of storing the knowledge for present and future use. The storage of knowledge (which is also known as "organizational memory") appears to be a major building block in implementing knowledge management so that knowledge can be created and reused. Memory can be defined as a hidden source of past experiences, detailed decisions, and their results, and the organization's response, rules, of thumbs and some un-written decisions that can be retrieved later for use and regulate current actions and decisions (El Saway, Gomes, \& Gonzalez, 1986). Similarly, Levinthal and March (1993), for example, suggested that when organizations learn, organizational knowledge becomes embedded in rules, procedures, technologies, beliefs, and cultures that also guide the 
future behavior, and this future behavior depends greatly on the methods by which the memory is maintained.

It is important for organizations to store the knowledge they gain over time because Olivera (2000) stressed that when an organization gains the ability to preserve the knowledge, it increases the probability of increased organizational performance. According to findings of Argote, Beckman, and Epple (1990), preserved knowledge can be helpful for organization in a way that it not only supports in framing and problem-solving, but also protects from chances of turnover.

It must be kept in mind that tacit knowledge is stored in the minds of individuals. According to Simon (1991), people in an organization are the most effective means of storing knowledge in the form of organization's experience. When people perform their work, they can generate a large amount of knowledge in their minds. Even though not a single or particular individual of the organization can be the only repository of memory of organization, but network of individuals can be a strong means of storage and retrieval of explicit knowledge (Olivera, 2000).

Explicit knowledge can be stored in computers and various objects; this knowledge can be retrieved by using different technologies. Different scholars like Ackerman and McDonald (1996), Anand, Manz, and Glick (1998), Huber (1991), Stein and Zwass (1995), and Olivera (2000) are of the view that sophisticated computer-based technology can be helpful in storing the knowledge which can be accessed easily when needed.

Technologies like shared electronic database and electronic bulletin boards are widely used systems to collect, store, and access the explicit knowledge. In addition to use of these technological systems, Lotus Notes are also used as primary tools for storing information in documents and to facilitate virtual groups (O'Leary, 1998).

Knowledge sharing. Knowledge exists at different levels in an organization. It prevails at individual, group, and organizational levels. Lam (2000) is of the view that individual knowledge is held in the minds and bodily skills of the individuals. According to Spender and Grant (1996), people's perspective of knowledge management reveals that individuals in an organization possess knowledge. This knowledge should not be concentrated to the individual level, but it must be moved and spread to the group level and then across the entire organization, so that it can be utilized to fulfill goals of the organization (Nonaka, 1994). Many authors are of the view that knowledge sharing results in knowledge creation, organizational learning, and improved performance (Bartol \& Srivastava, 2002). The ability of an organization to leverage knowledge depends entirely on the people in that organization who actually possess the knowledge. Knowledge can be best utilized only if is created, shared, and used by the people effectively in the organization. Knowledge sharing means knowledge is made available to other people in the organization. Davenport (1997) differentiated knowledge sharing from reporting. According to his findings, sharing is a voluntary act while reporting is exchange of information depending on structured formats. Sharing happens when an individual consciously exchanges knowledge with others and does it without any compulsion.

Knowledge sharing is a partnership in which there are two interested bodies: One possesses the knowledge while the other wants to acquire the knowledge. Knowledge sharing is quite important, because it establishes a connection between the individual and the organization as it moves the knowledge from the individual level to the organizational level. At the organizational level, the individual knowledge is converted into economic value and also it can become a competitive advantage for the organization (Hendriks, 1999). Knowledge sharing in an organization leads to many positive outcomes. It results in improved organizational performance in terms of individual and organization's learning (Andrews \& Delahaye, 2000). Therefore, knowledge sharing should be promoted in an organization, because its benefits outweigh the efforts made to share the knowledge. 


\section{Technology Infrastructure}

According to Gaffoor (2008), IT is one of the most important knowledge management enablers in every organization. Sophisticated technological infrastructure is a major factor that aids the efforts made by the organization to build a knowledge culture. For the success of knowledge management system, managing knowledge is vital for organizations. IT provides grounds for the utilization of knowledge by building the organization's infrastructure.

By using IT, collaboration, saving knowledge, and retrieval as components of IT, an effective knowledge management system can be developed. Sophisticated technology and communication system enables the users to access the knowledge and communicate with the knowledge experts. Collaboration technology ensures that all the activities and work are done collectively. Similarly, saving and retrieval technology ensures that knowledge is saved and recovered when desired (Turban, Leidner, Mclean, \& Wetherbe, 2006). It therefore confirms the importance of IT in managing knowledge.

IT is playing an important role in the management of knowledge. Through the use of technological infrastructure, it is possible to ease access to knowledge, creating a backup for knowledge reservoirs, thereby facilitating the knowledge system. IT plays a key role in knowledge creation activities as it acts as a knowledge creation tool in a scientific environment. It also enhances interaction in organization individually and collectively (Tian, Nakamori, \& Wierzbicki, 2009).

Knowledge management cannot be implemented without suitable IT tools, because IT is an important tool for knowledge management implementation. Research findings reveal that IT is a critical success factor for implementing knowledge management in an organization (Mobashar, Ahmad Kamil, Savita, \& Aamir, 2010).

A well-developed technological infrastructure can increase communication within the organization by removing difference obstacles of communication between various departments of the organization. It leads to the wide distribution of knowledge in the organization (Holsapple, 2006). Alavi (2006) is of the view that technology is the basic factor in creating and distributing knowledge.

Knowledge creation can be achieved with the help of technology (Gold et al., 2001). According to Raven and Prasser (1996), Scott (1998), and Zack (1999), technology infrastructure consists of IT and its capabilities. IT helps people connect with each other, thereby, facilitating conversation and sharing of ideas and information. It acts as a natural medium for the flow of knowledge and helps in knowledge reuse. Linkage of IT in an organization helps in the integration of fragmented knowledge.

In order to manage knowledge effectively, IT acts as an enabler and it also helps the organization see its full benefits (Ndlela \& Toit, 2001). IT within an organization helps to determine how knowledge is used and accessed (Leonard-Barton, 1995). Thus, the support of IT is essential for introducing and performing knowledge management. An organization should invest in a broad infrastructure that can support the various types of knowledge activities (Gold et al., 2001).

\section{Organizational Performance}

Previous findings of the researchers and scholars indicate that there is positive relationship between knowledge management and organizational performance (Gold et al., 2001; Gosh \& Scott, 2007; Lee \& Sukoco, 2007; Liu, Chen, \& Tsai, 2005; H. Zaim, Tatoglu, \& S. Zaim, 2007). Some researchers are of the view that knowledge infrastructure capability and knowledge management processes have a positive relation with the effectiveness of the organization. 
According to Lee and Sukoco (2007), knowledge management capabilities, like knowledge strategy, technology, etc., can result in improved organizational performance. Gosh and Scott (2007) claimed that technology, organizational culture, and organizational structure should be integrated with the knowledge management processes, i.e., flow and use of knowledge. Such integration can leads to an improvement in the organization's effectiveness. Zack, Mckeen, and Singh (2009) found that knowledge management practices have a positive relationship with the organizational performance resulting in learning, collaboration, and creativity of organization.

Organizational performance is positively influenced by knowledge infrastructure capability and knowledge process capability. Knowledge infrastructure capability means technology and culture of the organization. On the other hand, knowledge process consists of knowledge identification, storage, and sharing. Effectiveness of an organization can be analyzed from the outputs like organizational learning, collaboration, and creativity of individuals. Gold et al. (2001) claimed that both capabilities help in achievement of improved organizational performance.

However, some researches indicate that the role of knowledge management processes is not consistent. It can be seen that some findings show that both knowledge enablers and processes as antecedents of organizational performance. Knowledge management enablers and processes are independent variables of organizational performance (Becerra-Fernandez \& Sabherwal, 2001). It can be said that organizational performance depends on the technology employed in the organization and the knowledge management processes held in knowledge management system of the organization.

On the other hand, various studies reveal that technology as a knowledge enabler is pre-requisite of knowledge processes. Some researchers argue that technology is an independent variable of the knowledge management processes, i.e., knowledge identification, storage, and sharing (Appleyard, 1996; Hansen, 1999; Szulanski, 1996; Zander \& Kogut, 1995). Therefore, in the light of above argument, knowledge processes depend on the IT infrastructure of the organization.

Learning can be defined as acquiring new knowledge in the organization, so that people can apply this knowledge in influencing others and making important decisions (Miller, 1996). Hurley and Hult (1998) gave the definition of learning, according to which it is promoted and encouraged in the organization is known as learning. If an organization takes interest in the training and development of the individuals, it can result in learning, and individuals will be able to solve their problems by trying something new. Organizations should develop an effective learning culture by proving various tools of learning to the individuals like education, training, and mentoring. Learning can result in efficient knowledge processes (Swap, Leonard, Shields, \& Abrams, 2001). Therefore, if a sound knowledge infrastructure is established in the organization, it can result in individual learning which ultimately becomes organization's learning. Hence, the first hypothesis is that:

$\mathrm{H}_{1}=$ Organizational performance is significantly affected by technological infrastructure and knowledge management processes in terms of learning.

Collaboration can be defined as the extent to which people are willing to help and support one another in doing their work (Hurley \& Hult, 1998). In order to manage knowledge effectively, there is a need of collaboration in the organization. Organizational culture must be collaborative where people are ready to support each other (Gold et al., 2001).

Organizational knowledge can be created and managed effectively if there are collaborative practices, for example, open dialogues, discussions, and social networking (Nahapiet \& Ghoshal, 1998). Knowledge should 
be exchanged as it helps to increase collaboration and mutual support in people of an organization. When people in an organization actively exchange information and knowledge, it reduces fear and resistance among members and increase openness. Knowledge can be generated through such exchange and effective collaboration. Collaboration among organizational members also narrows individual differences (Leonard-Barton, 1995). Collaboration in an organization can help in developing a shared understanding of the organization's environment through a supportive and effective communication. Knowledge cannot be created and managed if there is lack of mutual understanding and collaboration among people of an organization (Fahey \& Prusak, 1998). It is therefore clear that in order to create and manage knowledge, collaboration is necessary. According to Hedlund (1994), knowledge management processes if managed effectively can result in strong collaboration, hence, the second hypothesis is that:

$\mathrm{H}_{2}=$ Organizational performance is affected by technological infrastructure and knowledge management process in terms of collaboration.

Organizational creativity can be defined as the ability of an individual to create useful and unique products, services, ideas, and processes by working collectively in a complex social system (Amabile, Conti, Coon, Lazenby, \& Herron, 1996; Woodman, Sawyer, \& Griffin, 1993). Knowledge plays a significant role in the ability of the organization to be creative (Vicari \& Troilo, 2000; Woodman et al., 1993). Hence, organizations with better knowledge management and diffusion are more creative. So, creativity in any organization also depends on how knowledge is managed there. Organizational creativity also joins and repositions knowledge and creates novel and unique ideas that are found to be useful by others (Koh, 2000). Creativity depends greatly on how knowledge is created and shared in the organization; it can be said that knowledge management processes play a role in creativity of an organization (Amabile et al., 1996). Several studies have examined the impact of knowledge infrastructure on organizational creativity. Koh (2000) claimed that organizational creativity is positively related to the knowledge infrastructure of the organization. The third hypothesis is that:

$\mathrm{H}_{3}=$ Organizational performance is significantly affected by technological infrastructure and knowledge management processes in terms of creativity.

This paper attempts to explain the possible relationship between knowledge infrastructure and organizational performance. Knowledge infrastructure consists of technological infrastructure and knowledge management processes. Organizational performance is reflected in terms of learning, collaboration, and creativity. In the conceptual model, knowledge infrastructure is taken as an independent variable while organizational performance is a dependent variable (see Figure 1).

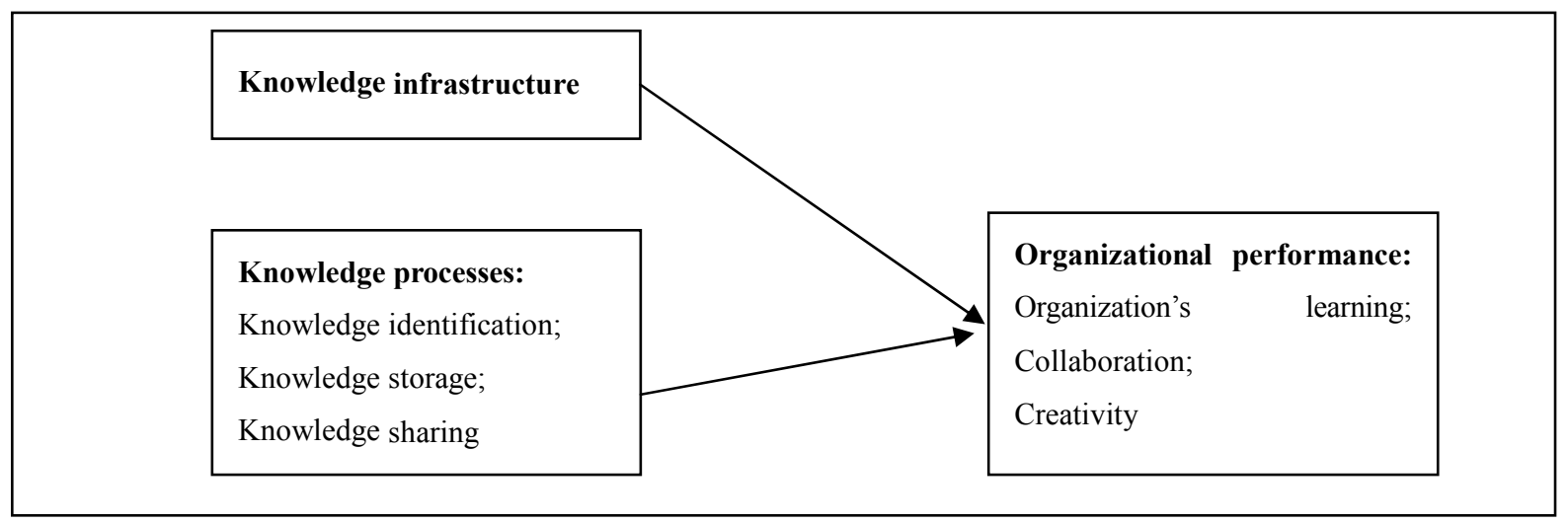

Figure 1. Conceptual model (Independent variable vs. dependent variable). 


\section{Methodology}

\section{Research Instruments}

In order to test the hypotheses, empirical research was conducted. A 5-point Likert scale questionnaire was designed and distributed to the teaching faculties of various universities. A total of 29 questions were asked about IT infrastructure, knowledge management processes, and organizational performance.

\section{Data Collection}

Education sector was chosen particularly to study the impact of knowledge management infrastructure on the performance. Various universities from areas of Lahore, Sahiwal, and Multan were targeted in this regard. Questionnaires were distributed to the teaching faculties of these universities. The total number of responses was 100. Random sampling method was selected particularly.

\section{Data Analysis and Results}

Reliability analysis is used to measure the stability and consistency of the concept and this analysis helps to assess the "goodness of a measure" (Sekaran, 1992, p. 173). Consistency means to what extent variables hang together as a set. One of the consistency tests is inter-item consistency reliability, and this is best achieved by using Cronbach's coefficient alpha. Cronbach's alpha indicates "How well the items in a set are positively correlated to one another" (Cavana, Delahaye, \& Sekeran, 2001, p. 321). In this case, Cronbach's alpha is 0.945 (see Table 1), which shows that internal validity of the research instrument is very good.

Table 1

Reliability Statistics

\begin{tabular}{ll}
\hline Cronbach's alpha & No. of items \\
\hline 0.945 & 29 \\
\hline
\end{tabular}

IT infrastructure, knowledge identification, knowledge storage, knowledge sharing, learning, collaboration, and creativity show strong relationship (see Table 2), therefore, it requires that these variables must be managed carefully in order to increase the performance of the organization. Preferably, a sophisticated IT infrastructure and knowledge management processes should be managed carefully to enhance the performance of the organization.

Table 2

Correlations

\begin{tabular}{|c|c|c|c|c|c|c|}
\hline & $\begin{array}{l}\text { IT } \\
\text { infrastructure }\end{array}$ & $\begin{array}{l}\text { Knowledge } \\
\text { identification }\end{array}$ & $\begin{array}{l}\text { Knowledge } \\
\text { storage }\end{array}$ & $\begin{array}{l}\text { Knowledge } \\
\text { sharing }\end{array}$ & Learning & Collaboration Creativity \\
\hline IT infrastructure & 1 & & & & & \\
\hline Knowledge identification & $0.628^{* *}$ & 1 & & & & \\
\hline Knowledge storage & $0.574^{* *}$ & $0.766^{* *}$ & 1 & & & \\
\hline Knowledge sharing & $0.484^{* *}$ & $0.668^{* *}$ & $0.686^{* *}$ & 1 & & \\
\hline Learning & $0.791^{* *}$ & $0.596^{* *}$ & $0.513^{* *}$ & $0.563^{* *}$ & 1 & \\
\hline Collaboration & $0.776^{* *}$ & $0.615^{* *}$ & $0.555^{* *}$ & $0.640^{* *}$ & $0.725^{* *}$ & 1 \\
\hline Creativity & $0.571^{* *}$ & $0.347^{* *}$ & $0.323^{* *}$ & $0.318^{* *}$ & $0.461^{* *}$ & $0.601^{* *}$ \\
\hline
\end{tabular}

Note. ${ }^{* *}$ Correlation is significant at the 0.01 level (2-tailed).

\section{Multiple Regression Model}

Results indicate that knowledge identification has less significance of $0.360,0.605$, and 0.700 (see Table 
3), which shows that there is less or no knowledge identification at all in most education institutions of Pakistan. Therefore, this factor requires considerable attention as knowledge without proper identification is hard to manage.

Table 3

Multiple Regression Results

\begin{tabular}{llccl}
\hline Dependent variable & Independent variable & Beta & \multicolumn{1}{l}{ Sig. } \\
\hline \multirow{4}{*}{ Learning } & IT infrastructure & 0.680 & 8.871 & 0.000 \\
& Knowledge identification & 0.093 & 0.919 & 0.360 \\
& Knowledge storage & -0.125 & -1.265 & 0.209 \\
& Knowledge sharing & 0.257 & 3.045 & 0.003 \\
\hline \multirow{5}{*}{ Collaboration } & IT infrastructure & 0.617 & 8.335 & 0.000 \\
& Knowledge identification & 0.051 & 0.519 & 0.605 \\
& Knowledge storage & -0.092 & -0.960 & 0.339 \\
Kreativity & Knowledge sharing & 0.370 & 4.535 & 0.000 \\
& IT infrastructure & 0.577 & 5.253 & 0.000 \\
& Knowledge identification & -0.056 & -0.386 & 0.700 \\
& Knowledge storage & -0.034 & -0.242 & 0.809 \\
\hline
\end{tabular}

Knowledge storage also shows less significant of $0.209,0.339$, and 0.809 , which shows that there is a desperate need of storage mediums in the education institutes of Pakistan. Storage of knowledge also requires strong consideration in order to increase the performance of the organization.

Knowledge sharing shows great significance of 0.003 and 0.000 for learning and collaboration. This indicates that there is sharing of knowledge results in learning and collaboration in the organization. Knowledge sharing, however, shows less significance of 0.411 for creativity in the organization which means less or no sharing in the educational institutes results in the lack of creativity. It therefore should be taken into consideration carefully by the educational institutes.

On the other hand, IT infrastructure shows more significance of 0.000 with learning, collaboration, and creativity. This level of significance shows a strong relation of IT infrastructure with learning, collaboration, and creativity. Hence, if there is a sophisticated IT infrastructure in an organization, it can ultimately result in improved organizational performance.

\section{Discussion and Conclusion}

In this study, the relationship between knowledge infrastructure and organizational performance was examined. The basic purpose was to find out the impact of technological infrastructure and knowledge management processes on the performance of the organization. All hypotheses are proved to be significant which in general shows that knowledge infrastructure positively affects the performance of the organization. If knowledge infrastructure is managed properly by the organization, it can enhance the performance of the organization which is evident from certain outcomes. These outcomes are increased organizational learning, collaboration, on various levels and creativity.

Knowledge management is an emerging concept, especially in a developing country like Pakistan, where people are not much familiar with this concept. In education sector of Pakistan, many universities recognize the importance of knowledge management and knowledge infrastructure. But due to some political factors, 
technological infrastructure is not appropriate to support the knowledge management processes. It is quite evident in the public universities which lack resources to invest in the technological infrastructure. On the other hand, some private universities manage to have adequate technological infrastructure to support their knowledge management processes. Even with the technological infrastructure, there is lack of knowledge identification in the education sector of Pakistan. This lack of knowledge identification results in less or no learning, collaboration, and creativity in the organization, thereby decrease in the overall performance of the organization. Knowledge should be stored for the future use and decision-making, but in most educational institutes of Pakistan, knowledge is not stored because of lack of a sophisticated technological infrastructure. When knowledge is not stored, it cannot be retrieved, thus it hinders the organizational learning as well. There is less collaboration and creativity because people in the organization do not have any knowledge at hand to share. Similarly, when knowledge is shared, it can result in learning of organization. Sharing of knowledge also promotes collaboration and increases the creativity of individuals, hence, it positively affects the overall performance of the organization. Unfortunately, there is less willingness in people to share knowledge perhaps because of lack of appropriate technological tools as well as their lack of knowledge about what to share.

In conclusion, it can be said that a well-managed technological infrastructure with knowledge management process facilitates organizational learning, collaboration, and creativity in the organization. So, knowledge infrastructure must be managed carefully in the educational institutes in order to enhance the performance. In Pakistan, people are not fully aware of the concept of knowledge management, all they perceive knowledge management just a technology. As a matter of fact, knowledge management is far more than technology. Therefore, efforts must be put forth to let people identify the knowledge and then knowledge management processes can be carried out easily.

\section{Limitations and Practical Implications}

The only limitation was ambiguity about the basic concept of knowledge management in most educational institutes of Pakistan. Technological infrastructure exists but it has to be more sophisticated in order to support the knowledge management processes. This ambiguity about knowledge management was the only hindrance in research.

This study will be helpful for the educational institutes of Pakistan to understand the current practices regarding knowledge management. It will help these institutes build a sophisticated knowledge infrastructure in order to enhance the performance. In future, this paper can act as guideline for carrying out various research studies about knowledge infrastructure.

There is political pressure on the public universities; a sufficient amount of budget must be allocated in order to implement different knowledge management programs. Then, awareness should be created among teachers as well as students about this concept. Training programs can be useful in helping the people understand the significance and basics of knowledge management. Once, the concept of knowledge management is clear, there will be less time to implement and run the knowledge management programs.

\section{References}

Ackerman, M. S., \& McDonald, D. W. (1996). Answer garden 2: Merging organizational memory with collaborative help. Proceedings of The ACM Conference on Computer Supported Cooperative Work (CSCW'96) (pp. 97-105).

Alavi, M. K. (2006). An empirical examination of the influence of organizational culture on knowledge management practices. Journal of Management Information System, 22(3), 191-224. 
Amabile, T. M., Conti, R., Coon, H., Lazenby, J., \& Herron, M. (1996). Assessing the work environment for creativity. Academy of Management Journal, 39(5), 1154-1184.

Anand, V., Manz, C., \& Glick, W. H. (1998). An organizational memory approach to information management. Academy of Management Review, 23(4), 796-809.

Andrews, K. M., \& Delahaye, B. L. (2000). Influences on knowledge processes in organizational learning: The psychological filter. Journal of Management Studies, 37(6), 2322-2380.

Appleyard, M. (1996). How does knowledge flow? Interfirm patterns in the semiconductor industry. Strategic Management Journal, 17(Winter), 137-154.

Argote, L., Beckman, S. L., \& Epple, D. (1990). The persistence and transfer of learning in industrial settings. Management Science, 36, 140-154.

Bartol, K. M., \& Srivastava, A. (2002). Encouraging knowledge sharing: The role of organizational reward systems. Journal of Leadership and Organization Studies, 9(1), 64-76.

Becerra-Fernandez, I., \& Sabherwal, R. (2001). Organizational knowledge management: A contingency perspective. Journal of Management Information Systems, 18(1), 23-55.

Cavana, R., Delahaye, B. L., \& Sekeran, U. (2001). Applied business research: Qualitative and quantitative methods. Milton, Australia: John Wiley and Sons.

Chen, C. W. (2011). Modeling and initiating knowledge management program using FQFD: A case study involving a healthcare institute. Quality \& Quantity, 46(3), 889-915.

Davenport, T. H. (1997). Information ecology. Oxford, U.K.: Oxford University Press.

El Saway, O. A., Gomes, G. M., \& Gonzalez, M. V. (1986). Preserving institutional memory: The management of history as an organizational resource. Academy of Management Best Paper Proceedings, 37, 118-122.

Ernst \& Young. (1998). Consulting methodology for knowledge management. Ernst \& Young Management Consulting.

Fahey, L., \& Prusak, L. (1998). The eleven deadliest sins of knowledge management. California Management Review, 40(4), 265-276.

Gaffoor, S. (2008). Assessing readiness for the implementation of knowledge management in local governments: The case of Stellenbosch Municipality (MCom thesis, School of Public Management and Planning, Faculty of Economic and Management Sciences, Stellenbosch University).

Gold, A. H., Malhotra, A., \& Segars, A. H. (2001). Knowledge management: An organizational capabilities perspective. Journal of Management Information Systems, 18(1), 185-214.

Gosh, B., \& Scott, J. E. (2007). Effective knowledge management systems for a clinical nursing setting. Information Systems Management, 24(1), 73-84.

Hansen, M. T. (1999). The search-transfer problem: The role of weak ties in sharing knowledge across organization subunits. Administrative Science Quarterly, 44, 82-111.

Hedlund, G. (1994). A model of knowledge management and the N-form corporation. Strategic Management Journal, 15, 73-90.

Hendriks, P. (1999). Why share knowledge? The influence of ICT on the motivation for knowledge sharing. Knowledge and Process Management, 6(2), 91-100.

Holsapple, C. W. (2006). Knowledge management: A three-fold. Information Society, 18(1), 47-64.

Huber, G. P. (1991). Organizational learning: The contributing process and the literatures. Organization Science, 2(1), 88-115.

Hurley, R., \& Hult, T. (1998). Innovation, market orientation, and organizational leaning: An integration and empirical examination. Journal of Marketing, 62(3), 42-54.

Jennex, M. E., \& Olfman, L. (2004). Assessing knowledge management success/effectiveness models. Proceedings of The 37th Hawaii International Conference on System Sciences, Hawaii.

Kiessling, T. S., Richey, R. G., Meng, J., \& Dabic, M. (2009). Exploring knowledge management to organizational performance outcomes in a transitional economy. Journal of World Business, 44, 421-433.

Koh, A. T. (2000). Linking learning, knowledge creation, and business creativity: A preliminary assessment of the East Asian quest for creativity. Technological Forecasting and Social Change, 64, 85-100.

Lam, A. (2000). Tacit knowledge, organizational learning and societal institutions: An integrated framework. Organization Studies, 21(3), 487-513.

Lee, H., \& Choi, B. (2003). Knowledge management enablers, processes, and organizational performance: An integrative view and empirical examination. Journal of Management Information Systems, 20(1), 179-228. 
Lee, J. H., \& Kim, Y. G. (2001, June). Effects of managerial drivers and climate maturity on knowledge management performance: Empirical validation. Proceedings of Pacific Asia Conference on Information Systems (pp. 1097-1111).

Lee, L. T., \& Sukoco, B. M. (2007). The effects of entrepreneurial orientation and knowledge management capability on organizational effectiveness in Taiwan: The moderating role of social capital. International Journal of Management, 24(3), 549-73.

Leonard-Barton, D. (1995). Wellsprings of knowledge: Building and sustaining the sources of innovation. Boston, M.A.: Harvard Business School Press.

Levinthal, D., \& March, J. G. (1993). The myopia of learning. Strategic Management Journal, 14(Winter Special Issue), 95-112.

Liu, P. L., Chen, W. C., \& Tsai, C. H. (2005). An empirical study on the correlation between the knowledge management method and new product development strategy on product performance in Taiwan's industries. Technovation, 25(7), 637-644.

Miller, D. A. A. (1996). Preliminary typology of organizational learning: Synthesizing the literature. Journal of Management, 22(3), 484-505.

Mobashar, R., Ahmad Kamil, B. M., Savita, K. S., \& Aamir, A. (2010, March). Implementation of knowledge management in small and medium enterprises. Journal of Knowledge Management Practice, 11(1).

Nahapiet, J., \& Ghoshal, S. (1998). Social capital, intellectual capital, and the organizational advantage. Academy of Management Review, 23(2), 242-266.

Ndlela, L. T., \& Toit, A. S. A. (2001). Establishing a knowledge management programme for competitive advantage in an enterprise. International Journal of Information Management, 21, 51-165.

Nevis, E., Anthony, D., \& Gould, J. (1995). Understanding organizations as learning systems. Sloan Management Review, Winter, 73-85.

Nonaka, I. (1994). The dynamic theory of organizational knowledge creation. Organization Science, 5(1), 14-37.

Nonaka, I., \& Takeuchi, H. (1995). The knowledge-creating company: How Japanese companies create the dynamics of innovation. Oxford, U.K.: Oxford University Press.

O’Leary, D. E. (1998, March). Enterprise knowledge management. Computer, 31(3), 54-61.

Olivera, F. (2000). Memory systems in organizations: An empirical investigation of mechanisms for knowledge collection, storage and access. Journal of Management Studies, 37(6), 811-832.

Probst, G., Raub, S., \& Romhardt, K. (2000). Managing knowledge: Building blocks for success. Chichester: John Wiley \& Sons Ltd..

Rajesh, R., Pugazhendhi, S., \& Ganesh, K. (2011). Towards taxonomy architecture of knowledge management for third party logistics service provider. Benchmarking: An International Journal, 18(1), 42-68.

Raven, A., \& Prasser, S. G. (1996). Information technology support for the creation and transfer of tacit knowledge in organizations. Proceedings of The AIS 1996 Conference.

Reinhardt, R. (2001). Knowledge management: From theory to practice. In D. Morey, M. Maybury, B. Thuraisingham, \& S. Thuraisingham (Eds.), Knowledge management: Classic and contemporary works. Cambridge, M.A.: MIT Press.

Riege, A. (2005). Three-dozen knowledge-sharing barriers managers must consider. Journal of Knowledge Management, 9(3), 18-35.

Robinson, H. S., Carrillo, P. M., Anumba, C. J., \& Al-Ghassani, A. M. (2005). Review and implementation of performance management models in construction engineering organizations. Construction Innovation, 5(4), 203-17.

Ruggles, R. L. (1997). Knowledge management tools. Boston, M.A.: Butterworth-Heinemann.

Santo, S. A. (2005). Knowledge management: An imperative for schools of education. TechTrends, 49, 42-49.

Scott, J. E. (1998). Organizational knowledge and the intranet. Decision Support Systems, 23(1), 3-17.

Sekaran, U. (1992). Research methods for business (2nd ed.). New York, N.Y.: Wiley.

Sher, P. J., \& Lee, V. C. (2004). Information technology as a facilitator for enhancing dynamic capabilities through knowledge management. Information \& Management, 41(8), 933-945.

Simon, H. A. (1991). Bounded rationality and organizational learning. Organization Science, 2(1), 125-134.

Spender, J. C., \& Grant, R. M. (1996). Knowledge and the firm: Overview. Strategic Management Journal, 17(S2), 5-9.

Stein, E. W., \& Zwass, V. (1995). Analyzing organizational with information systems. Information Systems Research, 6(2), 85-114.

Stewart, T. A. (2002). The case against knowledge management. Retrieved June 10, 2012, from http://www.iwp.jku.at/born/ mpwfst/06/cogneon/The_Case_Against_KM.pdf

Stukalina, Y. (2008). How to prepare students for productive and satisfying careers in the knowledge-based economy: Creating a more efficient educational environment. Technological and Economic Development, 14, 197-207. 
Swap, W., Leonard, D., Shields, M., \& Abrams, L. (2001). Using mentoring and storytelling to transfer knowledge in the workplace. Journal of Management Information Systems, 18(1), 95-114.

Szulanski, G. (1996). Exploring internal stickiness: Impediments to the transfer of best practice within the firm. Strategic Management Journal, 17(Winter), 27-43.

Tian, J., Nakamori, Y., \& Wierzbicki, A. P. (2009). Knowledge management and knowledge creation in academia: A study based on surveys in a Japanese research university. Journal of Knowledge Management, 13(2), 76-92.

Turban, E., Leidner, D., Mclean, E., \& Wetherbe, J. (2006). Information technology for management, transforming organizations in the digital economy (5th ed.). New York, N.Y.: John Wiley \& Sons.

Vicari, S., \& Troilo, G. (2000). Organizational creativity: A new perspective from cognitive systems theory. In G. Krogh, I. Nonaka, \& T. Nishiguchi (Eds.), Knowledge creation: A source of value (pp. 63-88). New York, N.Y.: St. Martin's Press.

Wiig, K. (1995). Knowledge management methods. Arlington, T.X.: Schema Press.

Woodman, R., Sawyer, J., \& Griffin, R. (1993). Toward a theory of organizational creativity. Academy of Management Review, $18(2), 293-321$.

Zack, M. H. (1999). Managing codified knowledge. Sloan Management Review, 40(4), 45-58.

Zack, M., Mckeen, J., \& Singh, S. (2009). Knowledge management and organizational performance: An exploratory analysis. Journal of Knowledge Management, 13(6), 392-409.

Zaim, H., Tatoglu, E., \& Zaim, S. (2007). Performance of knowledge management practices: A causal analysis. Journal of Knowledge Management, 13(6), 392-409.

Zander, D., \& Kogut, B. (1995). Knowledge and the speed of the transfer and imitation of organizational capabilities: An empirical test. Organization Science, 6(1), 76-92. 